Revista de Estudios Histórico-Jurídicos

[Sección historia del derecho patrio chileno]

XXXIX (Valparaíso, Chile, 2017)

[pp. 269 - 297]

\title{
GÉNesis de la DELEGaCión legislativa en Chile*
}

[Genesis of legislative delegation in Chile]**

\author{
Alan Bronfman VARGas*** \\ Pontificia Universidad Católica de Valparaíso, Chile
}

\begin{abstract}
RESUMEN
Este artículo revisa el ejercicio de la potestad legislativa delegada por el Congreso Nacional al Presidente de la República bajo el imperio de la Constitución de 1833. El trabajo demuestra que facultades extraordinarias genéricas fueron la base para dictar decretos legislativos y que ellas sólo se utilizaron de modo circunstancial para tal fin. Los decretos legislativos aprobados en el período son una simple manifestación de la voluntad política que permitió dictarlos. Ellos no son una respuesta racional ante una debilidad del proceso legislativo identificada
\end{abstract}

\begin{abstract}
This article reviews the exercise of legislative authority delegated by Congress to the President of the Republic under the rule of the Constitution of 1833. The work shows that the emergency powers that formed the basis to issue legislative decrees, were used only circumstantially for that end. Behind legislative decrees issued during the period there is no shared diagnosis about a problem in the ordinary legislative process. Therefore, birth of legislative decrees does not answer to a
\end{abstract}

RECIBIDO el 29 de julio y ACEPTADO el 10 de noviembre de 2016

* Tabla de abreviaturas: BLOD.: Boletín de las leyes y de las órdenes y decretos; BLODG.: Boletín de las leyes, órdenes i decretos del Gobierno; SCL.: Sesiones de los Cuerpos Lejislativos de la República de Chile.

** Este artículo forma parte del proyecto de investigación Fondecyt núm. 1151365, titulado Perspectivas para el desarrollo de la facultad de delegar la potestad legislativa en Chile en armonía con las exigencias de un régimen democrático representativo y de separación de poderes. El autor agradece la colaboración en la investigación y en este artículo de Mg. María Trinidad de la Maza Ovalle.

*** Profesor de derecho constitucional en la Pontificia Universidad Católica de Valparaíso. Dirección postal: Avenida Brasil núm. 2950, Valparaíso. Correo electrónico: alan.bronfman@ pucv.cl. 
y reconocida por los parlamentarios. En 1874 las facultades extraordinarias fueron reemplazadas por un régimen restrictivo de limitación de derechos.

Palabras Clave

Ley-Delegación - Potestad Legislativa - Potestad Reglamentaria - Facultades extraordinarias - Leyes Marianas Constitución de 1833. rational solution to a need identified by the political class.In 1874 these emergency powers were replaced by a restrictive regime of limitation of rights.

KEYWORDS

Act - Delegation - Legislative authority - Regulatory powers - Constitution of 1833.

\section{INTRODUCCIÓN}

La Constitución de 1833 no contenía ninguna disposición que autorizase, de modo explícito, la delegación de la potestad legislativa al Presidente de la República. Sin embargo, el artículo 36, dentro de las atribuciones exclusivas del Congreso, consideraba la de autorizar al Presidente para usar facultades extraordinarias. Decía el numeral 6o: "Autorizar al Presidente de la República para que use de facultades estraordinarias, debiendo siempre señalarse espresamente las facultades que se le conceden, i fijar un tiempo determinado a la duración de esta lei".

Esta norma autorizativa, en los hechos, fue el sustento constitucional de toda la legislación delegada dictada en el período 1833-1874. En este lapso se aprobaron por el Congreso Nacional cuatro leyes de facultades extraordinarias (1837, 1851, 1852 y 1859), una de prórroga de dichas facultades (1859), otra de caducidad de las mismas (1839) y una para mantener en vigor disposiciones dictadas en uso de facultades extraordinarias (1860). Ellas dieron lugar a más de ochenta cuerpos normativos de rango legal, sobre una amplia variedad de tópicos, algunos distantes de toda relación con circunstancias o situaciones excepcionales o de anormalidad constitucional.

El uso de estas facultades extraordinarias, en especial, para la aprobación de preceptos de rango legal -como las leyes marianas- fue criticado en el Congreso Nacional. De allí que en 1874 fuese aprobada una reforma constitucional que derogó la atribución exclusiva del Congreso Nacional del artículo 36 núm. 6º y que creó, en su reemplazo, un régimen de excepcionalidad constitucional que permitía al Presidente adoptar medidas de emergencia, más no normas legales de carácter general y permanente. En los párrafos que siguen explicaremos esta evolución.

\section{EL TEXTO DE 1833}

El numeral 6 del artículo 36 no se encontraba en la precedente Constitución de 1828. Es muy significativo, además, que el proyecto del 6 de abril de 1832 
no lo incluía ${ }^{1}$. Tampoco lo incluyeron los proyectos de Meneses y el atribuido a Gandarillas, los que disponían de otra solución ante la perturbación de la tranquilidad pública por ataque exterior, conjuraciones interiores o asonadas. En ambos proyectos, el Presidente de la República estaba dotado de facultades para adoptar providencias excepcionales con acuerdo del Consejo de Estado ${ }^{2}$.

El contenido del numeral 6 proviene del numeral 14 del artículo 57 del Voto Particular presentado por Mariano Egaña a la Comisión nombrada por la Gran Convención el 12 de mayo de $1832^{3}$. El Voto Particular contenía también la facultad presidencial de declarar estado de sitio en uno o varios puntos de la República, con acuerdo del Consejo de Estado y por un determinado tiempo ${ }^{4}$.

El Voto Particular, en este tópico, generó cierto rechazo. Así, en noviembre de 1832 un texto publicado en El Araucano criticaba la facultad de otorgar potestad extraordinaria al Presidente de la República: "En orden al uso de las facultades estraordinarias, no podemos dejar de opinar con el señor Constant que esta práctica puede ser en gran manera ominosa a la libertad, abriendo la puerta para que a la sombra de la lei se cometan mil arbitrariedades. ¿De cuántos ciudadanos virtuosos no puede deshacerse un Ministro que sepa manejar los resortes de la política? [...] Tamaños inconvenientes no se salvan ni con lo estraordinario de las circunstancias ni con el acuerdo previo del Congreso. Un ministro tiene sobrados elementos para preparar esas mismas circunstancias $i$ bastante influencia en el Cuerpo Legislativo para lograr, en virtud de ellas, la facultad que desea"'.

Luego, se temía no sólo por las facultades extraordinarias y su uso, sino que también por la forma en que éstas podían obtenerse por parte del Presidente.

En favor de la potestad propuesta por el Voto Particular se sostuvo que de todos modos el Congreso tenía dicha facultad de conferir poderes extraordinarios

1 Artículo 39 del proyecto redactado por la Comisión encargada de reformar el texto de 1828. Este proyecto sirvió de base para la discusión artículo por artículo de la Gran Convención. Bronfman, Alan, Documentos Constitucionales de Chile 1811-1833, en Dippel, Horst (ed.), Constitutions of the World from the late 18th Century to the Middle of the 19th Century (München, K. G. Saur Verlag GmbH, 2006), II, p. 184 y 185; CarrasCo Albano, Manuel, Comentarios sobre la Constitución Política de 1833 (Santiago, Imprenta de la Librería del Mercurio, 1874), p. 81. Tampoco se encuentra en el artículo 43 publicado en LeTELIER, Valentín, La Gran Convención de 1831-1833 (Santiago de Chile, Imprenta Cervantes, 1901), p. 50.

${ }^{2}$ Letelier, Valentín, cit. (n. 1), pp. 59 y 65. En el proyecto de Gandarillas el Senado podía, además, aprobar o reprobar medidas extraordinarias del Ejecutivo adoptadas en caso de conmoción interior, ataque exterior y en todos los que peligraba la seguridad pública, la conservación del gobierno o la subsistencia de la Constitución y las leyes (artículo 65). El mismo proyecto, en su artículo 48 núm. 14, entregaba al Congreso Nacional una facultad que no se mantuvo en el texto aprobado y que permitía al Congreso suspender momentáneamente actos del Poder Ejecutivo en "que se reconozca una grave i peligrosa resulta o violación de las leyes".

3 Bronfman, Alan, cit. (n. 1), p. 167.

${ }^{4} \mathrm{El}$ procedimiento general de declaración del estado de sitio respondía al caso de ataque exterior. En caso de conmoción interior la declaración correspondía al Congreso, sin perjuicio que si éste no se hallaba reunido, el acuerdo debía provenir del Consejo de Estado.

${ }^{5}$ El Araucano, núm. 112, 2 de noviembre de 1832. En otro artículo del mismo periódico se explica que, en época de elecciones, el ministro puede ordenar al intendente que fomente una conmoción y que luego proteste al Presidente, para que el Consejo de Estado declare estado de sitio y los “incautos provinciales” sufran destierro. LETELIER, Valentín, cit. (n. 1), pp. 137 y 188. 
y que la nueva norma restringía esta facultad "en favor de la libertad i seguridad de los ciudadanos”, pues obligaba a fijar de modo expreso las facultades otorgadas y el plazo de su vigencia ${ }^{6}$. El argumento se completaba señalando que si bien esta autorización podía ser fá c il o n e ce s a ria, la Constitución le exige que incluya el tiempo y "los objetos para que la concedían" como justificación adicional, la experiencia del uso moderado de estas facultades por parte de la administración en ejercicio y la anterior, aunque se reconocía que tal uso podía cambiar.

En lo formal, la propuesta de Egaña sobre facultades extraordinarias fue introducida en el debate vía indicación formulada en la sesión 33 de la Gran Convención (20 de diciembre de 1832) y fue aprobada en la sesión siguiente de la comisión. En esa misma sesión, la 34, Diego Arriarán propuso que esta autorización fuese otorgada con quórum de los dos tercios en cada cámara, lo que si bien se aprobó inicialmente, en definitiva no fue aceptado ${ }^{8}$. Asimismo, Vial Santelices pidió agregar a la norma que "las providencias que autorizare contra las personas no podrán exceder de un arresto o traslación a cualquier punto de la República”, indicación que quedó para segunda discusión. Si bien ella no se aprobó como parte de la norma de facultades extraordinarias, su contenido fue utilizado para limitar el poder conferido al Presidente de la República bajo estado de sitio (artículo 161 de la Constitución) ${ }^{9}$. Más adelante, en la sesión 64 (29 de abril de 1833), el Vicepresidente propuso agregar que, en el caso de concederse facultades extraordinarias al Presidente, éstas "no podrán estenderse hasta la de aplicar la pena de muerte" ${ }^{10}$. En la sesión siguiente se fundieron la propuesta de limitar el poder otorgado en estado de sitio y la de restringir las facultades extraordinarias, sumándose a la primera una referencia explícita a las facultades extraordinarias.

Como sea, la indicación de Egaña sobre ley de facultades extraordinarias fue aprobada por la Gran Convención, aunque, como señala Carrasco, lo fue con "gran contradicción i después de un largo debate en la primera i segunda discusión"11.

La disposición aprobada, entonces, permitía al Congreso Nacional autorizar el uso de facultades extraordinarias, bajo la condición de señalar expresamente las facultades concedidas y el tiempo en que ellas podían emplearse. El artículo 161 agregaba que estas facultades no autorizan al Presidente de la República a

${ }^{6}$ La Lucerna núm. 29, 9 de enero de 1833. Letelier, Valentín, cit. (n. 1), p. 256.

${ }^{7}$ Ibíd.

${ }^{8}$ Este quórum sumaba exigencias para la celebración de la respectiva sesión. Propuso Arriarán en la sesión 34 de la Gran Convención (21 de diciembre de 1832): "No podrá concederse esta autorización sin que se hallen presentes las tres cuartas partes del total de los miembros de cada una de las Cámaras". Letelier, Valentín, cit. (n. 1), p. 255.

${ }^{9}$ Según el artículo 161, declarado el estado de sitio se suspende el imperio de la Constitución en el territorio comprendido en la declaración. Durante la suspensión no puede la autoridad pública condenar por sí, ni aplicar penas. Las medidas que tomaré contra las personas no pueden exceder de un arresto o traslación a cualquier punto de la república. LeTELIER, Valentín, cit. (n. 1), p. 312.

${ }_{10}$ Ibíd.

${ }^{11}$ Carrasco Albano, Manuel, cit. (n. 1), p. 81. 
condenar por sí, ni aplicar penas, y que las medidas que adopte no pueden ser superiores al arresto o traslación a cualquier punto de la República ${ }^{12}$.

\section{Las facultades extraordinarias, sus limites y fundamento}

Las facultades extraordinarias previstas por el constituyente de 1833 en el numeral 6 del artículo 36 deben ser analizadas en al menos tres aspectos: el primero, el de su contenido en términos de potestades, atribuciones o competencias asignadas; el segundo el de sus límites; y tercero, el de sus fundamentos. El segundo y tercer aspecto tienen una íntima relación con el primero. Si la potestad de crear facultades carece de una referencia, función o directiva que permita prefigurar su contenido, existe una probabilidad que tanto límites como fundamento puedan carecer de funcionalidad jurídica. Como se explicará más adelante, la ausencia de una discusión explícita sobre el contenido de las facultades extraordinarias en el origen de la Carta de 1833, es un factor relevante para entender por qué los límites y fundamento previstos para su control tuvieron una limitada incidencia en su ejercicio efectivo.

La norma constitucional comentada no indicaba el tipo o contenido de las facultades extraordinarias que pueden conferirse por el Congreso Nacional. Tampoco las actas de sesiones de la Gran Convención ayudan a precisar el posible contenido de tales facultades entregadas al Presidente de la República. No obstante, el artículo 161, al mezclarlas con los límites del estado de sitio, las regulaba como si fuesen facultades extraordinarias de tipo jurisdiccional (o algún tipo de medidas de ejecución), ya que ante este tipo de facultades tienen sentido dichas restricciones ${ }^{13}$. Puede añadirse que, en lo formal, estas facultades se otorgaban mediante una ley (la que fija el tiempo determinado de su duración), lo que obliga a sostener que ellas no podían exceder el ámbito de las funciones y atribuciones previstas por la Constitución. Esta ley, según Huneeus, es solicitada por el Presidente quien requiere "la adopción de semejantes medidas", manifestando su absoluta necesidad ${ }^{14}$.

Carrasco Albano, en cambio, les asignaba un contenido preciso. Así, en sus Comentarios, que comenzó a escribir en 1855, las contrapone a las facultades ordinarias (o constitucionales) del Presidente de la República, para afirmar que estas facultades extraordinarias autorizadas por el Congreso Nacional no pueden coincidir con ninguna de aquellas ${ }^{15}$. Por otro lado, el mismo autor entiende que el Congreso Nacional no puede autorizar facultades no previstas por la Constitu-

${ }^{12}$ El artículo 161 señala como efecto de la declaración de estado de sitio la suspensión del imperio de la Constitución.

${ }^{13}$ La norma prohíbe "condenar por sî" y "aplicarpenas" al Presidente. Asimismo dispone que las medidas que tomare "en estos casos" (estado de sitio o ejercicio de facultades extraordinarias) contra las personas no pueden exceder de un arresto o traslación a cualquier punto de la República.

14 Huneeus, Jorge, La Constitución ante el Congreso (2a edición, Santiago, Imprenta Cervantes, 1890), I, p. 177.

15 Carrasco, Manuel, cit. (n. 1), p. 81. En 1849 se presentaron en la Cámara de Diputados dos mociones para regular las facultades extraordinarias. Precisamente, el proyecto refundido de ambas comenzaba con el listado de asuntos sobre los que no se podían conceder facultades extraordinarias. 
ción, pues de hacerlo se estaría arrogando la soberanía ${ }^{16}$. El Poder Legislativo sólo puede ejercer la parte de la soberanía que la Constitución le entrega, sin usurpar lo que corresponde a otros poderes o aquello que, simplemente, no tiene. Carrasco concluye "que la Constitución no ha querido sino facultar al Congreso para desprenderse de algunas de sus atribuciones lejislativas que ella misma designa, en favor del Ejecutivo" ${ }^{17}$. Carrasco, un poco más adelante, extendió el argumento a cualquier negocio que sea de la exclusiva competencia del Congreso.

El mismo jurista distingue las razones que legitiman estas facultades extraordinarias otorgadas por tiempo limitado. Si se trata de una guerra externa o un conflicto interno, el Ejecutivo ofrece una unidad de acción, secreto, rapidez y energía que el Congreso no puede entregar. En el curso ordinario de las cosas, por otro lado, es la complicación de los pormenores u otras causas que pueden hacer embarazosos ciertos asuntos, lo que justifica que las Cámaras se los encomienden al Presidente.

Por otro lado, Jorge Huneeus sostuvo que el Congreso sólo puede delegar sus atribuciones legislativas, pero no aquellas que le pertenecen como exclusi$\operatorname{vas}^{18}$. La misma tesis sostiene que se pueden delegar atribuciones legislativas que tienen utilidad para enfrentar una conmoción interior o guerra externa, a saber: imponer contribuciones ${ }^{19}$; gastar fuera de lo previsto en el presupuesto; aumentar la fuerza pública; crear o suprimir puertos mayores y aduanas en caso de guerra exterior; permitir la salida del territorio de tropas nacionales ${ }^{20}$. No es aceptable, según Huneeus, la delegación fuera de estos casos, en especial mediante leyes que otorgan facultades extraordinarias por largos períodos.

Como se indicó antes, los límites previstos por el constituyente al otorgamiento de facultades extraordinarias por el Congreso Nacional se ubican tanto en el propio numeral 6 del artículo 36 como en el citado artículo 161. El artículo 36 No 6 exigía señalar expresamente las facultades extraordinarias que se conceden al Presidente de la República y el plazo que tendrá la ley que las otorga, lo que inmediatamente relaciona dichas facultades con situaciones temporales o transitorias, pues de otro modo no se entiende dicha restricción ${ }^{21}$. El artículo

16 En el mismo sentido, refiriéndose a las leyes delegatorias por el Congreso, Roldán afirmaba que éste "[...] partía de un error, cual era creerse dueño de la soberanía, siendo que [...] no es él mismo sino delegado para ejercer esta soberanía dentro de los límites que le traza la Constitución”. RoldÁn, Alcibiades, Elementos de Derecho Constitucional de Chile (Santiago, Imprenta Barcelona, 1917), p. 339.

${ }_{17}$ Carrasco, Manuel, cit. (n. 1), p. 81.

18 Huneeus, Jorge, cit. (n. 14), p. 179.

19 Esto puede hacerlo porque el artículo 148 permite al Congreso otorgar una "especial autorización" para imponer contribuciones directas o indirectas.

${ }^{20}$ HuneEus, Jorge, cit. (n. 14), p. 180. Este autor no expresa ni fundamenta, en todo caso, por qué sólo estas facultades legislativas.

${ }^{21}$ Como se trata de satisfacer una necesidad transitoria (una situación anormal), su duración no puede ser indefinida, ni extenderse más allá del tiempo en que se mantienen dichas necesidades. Roldán se refiere a "situaciones anormales en que la salud pública o el bien general exigen que se provea a ese poder de nuevas facultades con cuyo auxilio se halle en aptitud de dominar las dificultades o trastornos consiguientes a esas situaciones”. RoldÁN, Alcibiades, cit. (n. 16), p. 337. 
161, como explicamos antes, al mezclar las restricciones impuestas al estado de sitio y las que corresponden a las facultades extraordinarias, impone a ambas la prohibición de condenar por sí o aplicar penas, y fija como límite a las medidas adoptables contra las personas el arresto o traslación a cualquier punto de la República. En los hechos, las restricciones del artículo 36 no fueron respetadas por las leyes de facultades extraordinarias (por ejemplo, la de 1837), aunque en lo referido al plazo de vigencia de tales facultades el legislador fue, paulatinamente, imponiendo criterios más rigurosos.

Por su parte, los límites del artículo 161 sólo afectaban el ejercicio de facultades de ejecución por parte del Presidente, pero no parecían tener utilidad ante el ejercicio de una potestad legislativa. De hecho, el Presidente, dotado de facultades extraordinarias creó consejos de guerra, los que funcionando como tribunales impusieron penas tan severas como la pena de muerte ${ }^{22}$.

El tercer aspecto relevante de la Constitución de 1833, en el tópico en análisis, es el fundamento para la instauración de una regla que permite otorgar facultades extraordinarias. Tanto el debate sobre la creación del artículo 36 núm. $6^{\circ}$ como el vínculo establecido en el artículo 161, sugieren la existencia de una relación directa entre excepcionalidad y facultades extraordinarias. Esta relación es esencial pues es el único fundamento, al menos el texto de la Carta Fundamental, que permite justificar la ruptura de la asignación de funciones y atribuciones prevista por el constituyente. Si este fundamento no existe o es objeto de una controversia, se pierde de vista el fin servido por estas facultades extraordinarias y su concesión, duración y alcance queda por completo entregada a una decisión política libre de restricción constitucional. Como se indicó arriba, todo el diseño y operación del edificio constitucional corre peligro si el Congreso puede entregar al Presidente facultades no previstas en la Constitución con total libertad y sólo sometido a la conveniencia o interés político o partidista.

En armonía con lo planteado, Huneeus entendía que las únicas circunstancias extraordinarias especiales que justificaban el uso de las facultades conferidas por el número 6 del artículo 36 de la Constitución, eran la necesidad de restablecer el orden público conmovido en el interior o la seguridad del país amenazada por una potencia extranjera ${ }^{23}$. La excepcionalidad o situación anormal tiene una incidencia importante en la extensión temporal de las facultades otorgadas.

Huneeus afirmaba que para otro tipo de necesidades legislativas existen otras herramientas y citaba como ejemplo el trabajo de los proyectos de Código Civil, de Código de Comercio y de ley de imprenta, todos los cuales se prepararon por comisiones especiales y luego se presentaron, discutieron y aprobaron por el Congreso. Este autor, sin negar la ineptitud del Congreso Nacional para elaborar cuerpos normativos extensos y complejos, plantea que existe un procedimiento eficaz alternativo para obtener el mismo resultado y que no introduce cambio al poder presidencial y parlamentario atribuido por la Constitución.

\footnotetext{
${ }^{22}$ En este caso, no ha sido el Presidente "por sî" el que ha condenado, ni quien ha impuesto una pena. Aunque sí sus subordinados.

${ }^{23}$ HuneEus, Jorge, cit. (n. 14), p. 180. Roldán lo plantea como "revolución e invasión del territorio nacional”. RoldÁn, Alcibiades, cit. (n. 16), p. 337.
} 


\section{La delimitación de las potestades legislativa y reglamentaria}

El siglo antepasado es el período histórico en que se construye el Estado de Chile. En este contexto, la precisa frontera entre el Poder Legislativo y la potestad reglamentaria fue una cuestión debatida en la doctrina y combatida en la política de la época. Dicho debate, en términos prácticos, intenta fijar el ámbito normativo autónomo del Presidente y el ámbito normativo en que el Congreso Nacional interviene ${ }^{24}$. En el primer siglo de historia como país independiente este debate tuvo, además, dos componentes adicionales: la ausencia de algunas herramientas conceptuales que ayudan a precisar dicho límite, desarrolladas con posterioridad, y la todavía incipiente institucionalización de ambas Cámaras y de la magistratura presidencial, que inciden en cierta incertidumbre en el reconocimiento de los poderes propios y ajenos. La ausencia de claridad sobre esta frontera es particularmente manifiesta en la regulación de la organización de la administración pública. En el tópico que analizamos, el carácter difuso de la frontera entre ley y reglamento disminuye la necesidad de acudir a facultades legislativas extraordinarias o delegadas, en la medida en que se admite que el Presidente regule materias que podrían ser legales mediante simples instrumentos reglamentarios.

Con una mirada amplia, puede comprobarse que, en los períodos estudiados, el Presidente ejerció potestades normativas propias próximas a lo que en el presente se consideraría como ámbito material reservado a la ley. Por lo pronto, se aprobaron varias leyes que autorizaban al Presidente a dictar normas de carácter general. Pueden destacarse aquí, a modo de ejemplo, la ley de 2 de septiembre de 1835, que facultó al Presidente de la República a promover la construcción de caminos, canales y puentes ${ }^{25}$. También es significativa la ley que autorizó al Presidente de la República a reformar el nuevo reglamento de la Aduana de Valparaíso ${ }^{26}$. Asimismo, el artículo 112 de la ley de municipalidades autorizó al Presidente a regular la obligación de los dueños de fundo de denunciar montoneras, bajo distintas

${ }^{24} \mathrm{El}$ ámbito de la ley sólo estaba fijado en su contenido mínimo por el artículo 37 de la Constitución y por otras referencias a la ley en el mismo texto fundamental.

25 Extendidas en 1841. Letelier, Valentín, SCL. (Santiago, Imprenta Cervantes, 1906), XXXIX, pp. 399, 400; y SCL. (Santiago, Imprenta Cervantes, 1905), XXX, pp. 7, 8, 350.

${ }^{26}$ LeTELIER, Valentín, SCL. (Santiago, Imprenta Cervantes, 1906), XXXIX, pp. 390, 408, 415, 419 y SCL. (Santiago, Imprenta Cervantes, 1905), XXX, p. 16. Esta Ley nació de un Mensaje del Presidente de la República en que solicitó ser investido de la facultad de reformar el nuevo reglamento de la Aduana de Valparaíso. Este Mensaje indica que no se trata del ejercicio de una potestad reglamentaria que el Presidente ya tenía por el artículo $82 \mathrm{~N}^{\circ} 2$ de la Constitución. El Congreso ratificó que se trata de un asunto legislativo al nombrar una comisión de tres individuos para examinar el reglamento de reforma preparado por el Presidente de la República. La ley de 29 de diciembre de 1841 autorizó al Presidente "para dictar todas las reglas" atingentes al manejo de la administración de la aduana de Valparaíso, lo que incluía aumentar o disminuir el número de empleados de la aduana y fijar sus remuneraciones. El plazo otorgado para hacerlo fue de ocho meses, lo que ratifica el carácter legislativo de la facultad conferida al Presidente. Años después, la ley del 13 de agosto de 1859 volvió a autorizar al Presidente para reformar la Ordenanza de Aduanas, por un período máximo de seis meses. El Presidente utilizó la autorización de 1859 el 23 de septiembre del mismo año para prohibir ingreso de armas sin un permiso especial. BLODG. (Santiago de Chile, Imprenta Nacional, 1860), XXVIII, pp. 111, 131 y 132. 
penas de multa ${ }^{27}$. Es posible añadir a este listado ejemplar, la moción del diputado Palazuelos, quien el 14 de septiembre de 1842 propuso autorizar al Presidente de la República a dictar un "reglamento con fuerza de ley" para determinar los deberes de amos y criados y demás sirvientes ${ }^{28}$. Un par de años más tardes, en 1845 , por medio de un mensaje, el Presidente de la República solicitó autorización para dictar una ordenanza del gremio de jornaleros y lancheros, la que le fue otorgada mediante la aprobación del proyecto de ley pertinente ${ }^{29}$.

En armonía con lo explicado, Valentín Letelier afirmaba que desde mediados de siglo XIX el Congreso Nacional chileno toleraba la invasión presidencial en tres materias reservadas a ley: creación y supresión de empleos públicos, asignación de sueldos y fijación de sus atribuciones ${ }^{30}$. Esta tolerancia tenía como límite la modificación de servicios públicos instituidos por ley, los que, por cierto no podían alterarse mediante simple decreto. Pero se aceptaba la creación de nuevos servicios vía decreto o la modificación de los existentes por la misma vía, siempre que estos últimos tuviesen su origen en simples decretos, en el entendido que esta medida resultaba fundada en las facultades generales de gobierno y administración confiadas al Presidente por el artículo 72 de la Constitución. Esta tolerancia resultaba explícita cuando el Congreso Nacional, por medio de la sanción de la ley de presupuestos, asignaba partidas presupuestarias a los servicios creados por esta vía, ratificando su existencia al margen de normas legales ${ }^{31}$. Agreguemos que la potestad presidencial en esta materia orgánica parecía muy difícil de cuestionar

${ }^{27}$ BLODG., cit. (n. 26), pp. 49-51.

${ }^{28}$ La moción proponía autorizar al Presidente de la República para promulgar una "ordenanza con fuerza de ley" para establecer los deberes mutuos de amos y criados, regular los juzgados correccionales pertinentes e imponer penas y órganos de supervisión. LETELIER, Valentín, SCL. (Santiago, Imprenta Cervantes, 1905), XXX, pp. 200, 201 y 288. Dicha moción fue desechada finalmente en la Cámara de Senadores por 18 votos contra 17, el 16 de junio de 1845. Él mismo, SCL. (Santiago, Imprenta Cervantes, 1908), XXXVII, pp. 38 y 41.

${ }^{29}$ Nuevamente se trata de un asunto que, de pertenecer al campo reglamentario, no exigiría autorización legislativa. LETELIER, Valentín, SCL (Santiago, Imprenta Cervantes, 1908), XXXVII, p. 428; y SCL. (Santiago, Imprenta Cervantes, 1908), XXXVI, p. 513.

${ }^{30}$ Huneeus piensa que esta invasión se repite: "si nosotros quisieramos acumular aquí los casos en que el Ejecutivo se ha arrogado en sus decretos facultades legislativas, tendríamos materia para llenar con ellos muchas páginas". Pero no quiere criticar a Congresos que se han "manifestado bien poco celosos de sus atribuciones". Letelier, Valentín, Génesis del Estado y de sus instituciones fundamentales. Introducción al estudio del derecho público (Buenos Aires, Cabaut y Cia. Editores, 1917), p. 489; Huneeus, Jorge, La Constitución ante el Congreso (2a edición, Santiago, Imprenta Cervantes, 1891), II, p. 49.

${ }^{31}$ Letelier menciona el Cuerpo de Ingenieros Civiles (1843), la Delegación Fiscal de Salitreras (1887), la Dirección General de Prisiones (1889), el Consejo de Higiene (1889), los correos, los telégrafos, los establecimientos de instrucción pública y casi todos los servicios del Estado. Jara, en una obra posterior alude a los "decretos incorporados" que son aquellos frutos de la potestad reglamentaria i n d e p e n d i e n t e del Presidente adoptados para la buena marcha de la administración (por ejemplo, sobre una necesidad pública) y que posteriormente son ratificados por el Congreso que crea el servicio pertinente. Letelier, Valentín, cit. (n. 30), p. 490; Jara Cristi, Manuel, Derecho administrativo. Notas de clases y anexos legislativos (Santiago, s. e., 1936), p. 107. 
en aquellos casos en que el nuevo cargo u oficina no suponía aumento de gastos ${ }^{32}$. No obstante lo anterior, puede comprobarse que incluso en aquellos casos en que no había gastos, la tolerancia antedicha era feble. Así, en diciembre de 1871 los diputados Gallo y Puelma cuestionaron la designación de Maximiliano Errázuriz como ministro plenipotenciario en Viena, pese a que el cargo creado carecía de remuneración, lo que llevó al Congreso, en definitiva, a rechazar su creación ${ }^{33}$.

En opinión de Letelier, la facultad normativa general presidencial no se agota con la ejecución de las leyes y la potestad reglamentaria ordinaria, sino que debía extenderse a lo que él denomina potestad política ${ }^{34}$. Tal potestad sirve para la conservación del orden "dentro o fuera de ellas", la organización de los servicios “con o sin la cooperación legislativa” y la fijación de los rumbos del Estado ${ }^{35}$. En el tópico que estudiamos tiene particular relevancia afirmar, como lo hace Letelier, que existe una potestad política que fundamenta expedir decretos orgánicos y que ella es inherente al gobierno ${ }^{36}$. Según esta tesis, las leyes no pueden darla ni quitarla al Presidente, quien la posee sólo por el hecho de existir: las leyes sólo podrían restringirla o ampliarla, y hasta cierto punto, reglamentarla. Lo anterior no significa que el decreto pueda actuar contra la ley o sin subordinarse a ley expresa, sino simplemente, que puede actuar fuera del campo de lo regulado por la ley en el terreno de esta potestad política. La doctrina de Letelier, aunque no sea compartida, puede ser utilizada para entender la actividad normativa general del período conservador, en el cual, con o sin tolerancia política deliberada, el Presidente dictó decretos sobre materias propias de ley.

Como puede suponerse, los partidarios de un Congreso fuerte no aceptaban una interpretación tan amplia de la potestad normativa general presidencial. Jorge Huneeus observaba que "la opinión de que el Ejecutivo puede crear, por medio de simples decretos, empleos públicos no retribuidos, no tiene base en la Constitución, y ella ha suscitado protestas en más de una ocasión" ${ }^{37}$. Según este tratadista, de admitirse la facultad presidencial de crear cargos públicos no remunerados, el Presidente podría crear "un ejército pagado por sus amigos", lo

${ }^{32}$ Letelier menciona la Junta de Vacuna (1830), la Oficina Central de Estadística (1843), el Servicio de Giros Postales (1868), la Oficina de Canje de Publicaciones (1871), la Oficina General de Inmigración (1872), y la Oficina Hidrográfica (1873).

33 El diputado Cood sostuvo que el Presidente estaba facultado para designar tal cargo, precisamente porque el cargo no tenía sueldo y por la facultad constitucional del Presidente para designar agentes diplomáticos y consulares. El Congreso rechazó esta interpretación. HEISE GonZALEZ, Julio, Evolución histórica del pensamiento parlamentario en Chile (Santiago, Academia Chilena de Ciencias Sociales-Instituto de Chile, 1986), p. 25.

${ }^{34}$ Letelier, Valentín, cit. (n. 30), p. 482.

35 Ibíd.

36 Según Letelier, el terreno más amplio para la potestad política es el del orden administrativo o de derecho administrativo. No sólo porque la administración se crea y desarrolla por obra del gobierno, sino que también porque la regulación mira a los empleados públicos "y no esconde peligro alguno para los derechos privados ni para las libertades públicas”. Ibíd., p. 488.

37 HuneEus, Jorge, cit. (n. 14), p. 239. 
que priva al Congreso de la intervención superior en los negocios del Estado que la Constitución le reserva ${ }^{38}$.

Por último, cabe notar que en textos del siglo XX referidos a la Constitución de 1833 se afirma que la remisión hecha en la ley a un "reglamento especial" configura una especie de delegación. Esta tesis explica con dicha remisión que el legislativo se desprende de su facultad de legislar sobre una materia propia de la ley y delega en el Presidente de la República "su atribución para que la ejercite discrecionalmente" ${ }^{39}$. El reglamento así elaborado "es fruto de la delegación del legislativo y se refiere a materias propias de la ley, no puede ser modificado o reformado por el Presidente" ${ }^{40}$. Pasa a tener, según Jara, el mismo carácter que la ley y sólo una ley podría enmendarlo o dejarlo sin efecto. Aunque hay dudas sobre la constitucionalidad de la delegación así configurada, ella fue aceptada en la práctica y en la jurisprudencia ${ }^{41}$.

\section{LAS LEYES DE FACULTADES EXTRAORDINARIAS Y SU PRÁCTICA. Primer PERÍODo (1833-1839)}

En el período 1833-1874 se aprobaron seis leyes que concedieron facultades extraordinarias al Presidente de la República. En la práctica, el cumplimiento de las exigencias del numeral $6^{\circ}$ del artículo 36 por el legislador fue parcial. Algunas de estas leyes no cumplían con la obligación de detallar el contenido de las facultades extraordinarias, en tanto otras no fijaban un plazo para su ejercicio (por lo que fue necesario en algún caso dictar una ley de caducidad). En fin, varias de estas leyes se centraban más en eximir de ciertas obligaciones constitucionales al Presidente, que en la regulación de los límites de las facultades concedidas.

La primera ley que concedió facultades extraordinarias al Presidente de la República se dictó tres meses después de la entrada en vigor de la Constitución (31 de agosto de 1833). En ella se argumentaba que en los cinco meses que preceden a su aprobación se habían descubierto tres conspiraciones para destruir el gobierno existente $^{42}$. En armonía con las ideas que parecen inspirar a los constituyentes, las facultades extraordinarias concedidas se dirigían a fortalecer el poder presidencial para mantener el orden público: arrestar o trasladar a cualquier punto de la República y procesar sin sujetarse a lo prevenido en los artículos 139, 143 y 146.

${ }^{38}$ Huneeus, Jorge, cit. (n. 14), p. 240 y 241. Comenta que "la pendiente del abuso es resbaladiza". Reconoce que el caso de creación de cargos "ha ocurrido más de una vez".

39 JARA, Manuel, cit. (n. 31), p. 106.

40 Ibíd.

41 Ibíd.

42 Esto sucedió apenas promulgada la Constitución. El 30 de agosto el ministro del Interior se presentó al Senado denunciando una nueva conspiración. Entre julio de 1833 y 1837 Villalobos cuenta seis confabulaciones significativas: la revolución de los puñales (julio de 1833), la expedición del general Freire (agosto de 1836), la revolución de los cadetes (noviembre de 1836), la conspiración del Ejército del Sur (enero de 1837), la conspiración de Curicó (marzo de 1837), y el levantamiento de Vidaurre en Quillota (junio de 1837). VilLaLobos R., Sergio, Portales. Una falsificación histórica (4a edición, Santiago, Universitaria, 2005), p. 191. 
La Ley, redactada por Mariano Egaña, las concedió hasta el $1^{\circ}$ de junio de 1834 y sometió su ejercicio al acuerdo de la mayoría de los ministros de despacho ${ }^{43}$.

La segunda ley que otorga facultades extraordinarias fue la de 9 de noviembre de 1836, que facultó al Presidente de la República para arrestar o trasladar a cualquier punto de la República, proceder sin sujetarse a las formalidades prevenidas en los artículos 139, 143 y 146, y dar órdenes a intendentes y subalternos referidas al ejercicio de estas facultades extraordinarias ${ }^{44}$. Estas facultades extraordinarias no incluían potestad legislativa alguna y, de hecho, luego de su aprobación el Congreso Nacional aprobó tres actos legislativos sucesivos en uso de sus facultades legislativas ordinarias (noviembre 10, diciembre 26 y enero 27). El último de estos actos legislativos contenía disposiciones que facilitaban la acción del gobierno contra sus enemigos, pues sancionaba a los desterrados por sedición, conspiración o motín, con la pena de muerte si quebrantaban su condena o destierro. Es más: la ley ordenaba que una vez detenidos los infractores debían ser fusilados en el plazo de veinticuatro horas, sin más proceso que el requerido para comprobar su identidad ${ }^{45}$.

La relativa irrelevancia de las facultades extraordinarias como fuente de potestad normativa general cambió de modo radical con la tercera concesión de facultades extraordinarias, aprobada por la ley de 31 de enero de 1837, sólo tres días después de la aprobación de la ley que fijaba pena de muerte para los desterrados infractores de su condena. Se trata de una ley de facultades extraordinarias abierta en términos de sus contenidos y plazo que, junto con declarar el estado de sitio por el tiempo que durase la guerra con Perú, autorizaba al Presidente a utilizar "todo el Poder Público que su prudencia hallare necesario para regir el Estado", con la única limitación proveniente del artículo 161 (no condenar por sí, ni aplicar penas), sanciones que sí podían emanar de los Tribunales establecidos o de los que "en adelante estableciere el mismo Presidente" ${ }^{\$ 6}$. Esta ley de 1837 no fijó un plazo de término de las facultades y por ello fue necesario dictar un decreto, en 1839, que dispuso la caducidad de dichas potestades extraordinarias ${ }^{47}$. La amplitud de esta

$43 \mathrm{Al}$ menos dos de ellos debían suscribir las resoluciones que se adoptasen. Agreguemos que la ley fue calificada de innecesaria y peligrosa por El Mercurio y de amenazadora para la tranquilidad de los ciudadanos por El Valdiviano Federal. El Araucano, en respuesta, sostuvo la ineficacia de las leyes comunes para juzgar a los reos de conspiración.

${ }_{44}$ Obligación del funcionario que decreta el arresto de poner al arrestado a disposición del juez dentro de las cuarenta y ocho horas siguientes al arresto (art. 139); posibilidad de interponer recurso de amparo (art. 143); e inviolabilidad del hogar (art. 146). BLOD. (2a edición, Santiago de Chile, Imprenta de la Independencia, 1841), VII, p. 62.

45 Ibíd., pp. 63 y 64.

46 Ibíd., cit. (n. 46), p. 73. Salazar, siguiendo a Vicuña Mackenna, relaciona esta ley de facultades extraordinarias con la ley del 27 de enero de 1837, que también formaría parte de las leyes marianas. SALAZAR, Gabriel, Construcción de Estado en Chile (1800-1837) (Santiago, Sudamericana, 2005).

${ }^{47}$ La norma que cierra la utilización de las facultades extraordinarias es de 31 de mayo de 1839. Con la misma fecha se aprobó un indulto general que junto con señalar el término de la guerra con el Perú declara la "reunión ordinaria del Congreso y el restablecimiento del orden constitucional”; BLOD. (2a edición, Santiago de Chile, Imprenta de la Independencia, 1841), VIII, pp. 152, 177 y 178). Su texto es un ejemplo más de la primacía de decisiones políticas 
ley hizo que sólo siete meses después de su aprobación se presentase una moción para limitar las facultades concedidas ${ }^{48}$.

La ley de facultades extraordinarias del 31 de enero de 1837 no determinó las facultades que se otorgaban al Presidente, lo que permitió a éste aprobar tanto decretos propios de una potestad ejecutiva extendida o ampliada, como también emitir actos jurídicos que invadían las competencias propias de la jurisdicción y del Congreso Nacional ${ }^{49}$. El Presidente de la República, en virtud de estas facultades extraordinarias creó tribunales (lo que según los artículos 108 y 109 de la Constitución correspondía a la ley), conmutó penas, aprobó normas penales y otorgó concesiones, entre otras materias ${ }^{50}$. En opinión de Huneeus, la ley del 31 de enero de 1837 permitió al Presidente legislar sobre toda materia entre los años 1837 y 1839 y hizo que el Congreso desapareciese de Chile en este bienio ${ }^{51}$. Cabe notar que entre enero de 1837 y mayo de 1839, el Boletín de leyes, órdenes $y$ decretos sólo registra tres decisiones del Congreso Nacional, una que regula la deuda interna y dos destinadas a rendir un homenaje a servidores públicos ${ }^{52}$. En

sobre criterios jurídico técnicos. Por lo pronto, se trata de una norma aprobada por el Presidente de la República destinada, en lo principal, a rehabilitar a generales y oficiales separados del servicio después de la revolución de 1830 . Ahora bien, si se trata de poner término a las facultades extraordinarias debió aprobarse un acto legislativo por el Congreso y no, simplemente, suscribirse un decreto por el Poder Ejecutivo. Su naturaleza mixta queda reflejada en su texto, ya que primero se utiliza la terminología "la presente lei" y más adelante, se alude al "presente decreto" (justamente para declarar cerrado el uso de las facultades extraordinarias). Lo suscriben Prieto y Mariano de Egaña y es uno de los decretos del período en que no se invocan, de modo explícito, las facultades extraordinarias concedidas en enero de 1837.

${ }^{48}$ Moción de Manuel José Gandarillas, presentada el 10 de agosto de 1837. Gandarillas proponía volver al listado de facultades extraordinarias de la ley del 9 de noviembre y disponer que las medidas sólo tuviesen vigor durante las sesiones ordinarias del Congreso. Propuso, además, que todos los actos librados por el Presidente de la República "con el nombre de leyes" quedasen suspendidos hasta que fuesen revisados, discutidos y acordados constitucionalmente. En la sesión del 25 de agosto se acordó que la moción no fuese admitida a discusión, pues no se encontraba presente Gandarillas. LeTeLIER, Valentín, SCL, Cámara de Senadores 1836-1838 (Santiago, Imprenta Cervantes, 1903), XXV, pp. 403, 404 y 406.

${ }^{49}$ El decreto del 11 de septiembre de 1837 modifica un auto acordado de 1799. Varios decretos del período, como se comentará, modifican de modo explícito leyes vigentes. $B L O D$., cit. (n. 44), p. 188.

${ }^{50} \mathrm{La}$ facultad de juzgar las causas civiles y criminales pertenece exclusivamente a los tribunales establecidos por la ley (art. 108). Sólo ésta puede innovar en las atribuciones de los tribunales y el número de sus integrantes (art. 109).

${ }^{51}$ Roldán opina lo mismo: "De acuerdo con esta ley, desapareció el Congreso y el Presidente quedó erigido en dictador. Este estado de cosas se mantuvo durante dos años". Roldán, Alcibíades, cit. (n. 16), p. 338.

${ }^{52}$ Se trata de una ley sobre deuda interior de 2 de febrero de 1837 y de dos decisiones del 8 de agosto de 1837, dirigidas a homenajear a Diego Portales y a Agustín Eizaguirre. La regulación de la deuda interior es modificada el 14 de febrero de 1837, por un decreto que invoca facultades extraordinarias. Un decreto de 17 de julio de 1839 regula la misma materia sin fundamento de facultades extraordinarias (que habían sido cerradas el 31 de mayo del mismo año). BLOD., cit. (n. 44), pp. 67, 183 y 184 y BLOD., cit. (n. 47), p. 187. 
1837 ambas Cámaras registran sólo diez sesiones en total y la Comisión Conservadora tres, y en 1838 sólo una ${ }^{53}$.

En virtud de la ley de facultades extraordinarias de 1837 se dictaron al menos sesenta y ocho decretos que pueden considerarse con fuerza de ley por el hecho de invocar dichas facultades ${ }^{54}$. La atribución de carácter legislativo de estos decretos, entendemos, puede deducirse de su referencia a facultades extraordinarias, pues si ellas no son mencionadas es posible suponer que se trata de decretos emanados de la potestad reglamentaria que pertenece por mandato constitucional al Poder Ejecutivo. Sin embargo, el examen de los decretos emitidos en el período revela cierta irregularidad en el empleo del fundamento normativo facult ades extra ordin a ri as como sustento de la potestad para aprobarlos ${ }^{55}$. Esto es: no en todos los casos en que parece pertinente, el Presidente funda sus decretos en las facultades extraordinarias concedidas el 31 de enero. Así, por ejemplo, el Presidente dicta algunos decretos que crean tribunales $\mathrm{u}$ otorgan competencias jurisdiccionales sin invocar facultades extraordinarias ${ }^{56}$. Asimismo, sin mencionar sus facultades extraordinarias, el Presidente suscribe algunos decretos que regulan asuntos procesales de relevancia ${ }^{57}$, crean órganos permanentes del Estado ${ }^{58}$, esta-

53 Letelier, Valentín, SCL., Cámara de Senadores 1836-1838 (Santiago, Imprenta Cervantes, 1903), XXV, pp. 473-479.

${ }^{54}$ Si fuesen actos propios de la potestad del Poder Ejecutivo no sería necesario ampararlos en las facultades extraordinarias. Como sea, precisar su número no es fácil, pues no todos los decretos prima facie legislativos invocan de modo explícito la ley que confiere facultades extraordinarias. Nosotros hemos optado por contabilizar sólo aquellos que las mencionan de modo expreso. A este número podrían sumarse algunos decretos que aluden a "las facultades que me están concedidas" (de 28 de diciembre de 1837), o "en uso de las facultades de que se halla investido" (13 febrero de 1838), o "en uso de las facultades que invisto" (29 de noviembre de 1838), e incluso aquellos que por su naturaleza o materia deben considerarse de rango legal (como el citado del 31 de mayo de 1839). Estévez contabiliza setenta y uno, pero pueden llegar hasta ochenta si utilizamos los criterios indicados. Estévez Gazmuri, Carlos, Elementos de derecho constitucional chileno (Santiago, Editorial Jurídica de Chile, 1949), p. 65; BLOD., cit. (n. 44), p. 212 y BLOD., cit. (n. 47), pp. 10, 91 y 177.

55 Irregularidad amparada por la ausencia de mecanismos de control político ejercidos desde el Congreso Nacional.

56 Como el que otorga competencias a los alcaldes suplentes (31 de julio de 1838) o los que crean el juzgado de letras de Copiapó (13 de octubre de 1838), el juzgado de comercio en la provincia del Maule (8 de enero de 1839), el consulado de Valparaíso (29 de mayo de 1839), el juzgado de abastos (31 de mayo de 1839), o el que extiende a los tribunales de consulado de Santiago la regulación de Valparaíso (31 de mayo de 1839). BLOD., cit. (n. 44), pp. 67, 183 y 184 y BLOD., cit. (n. 47), pp. 59, 79, 109, 144, 151, 152 y 187.

${ }_{57}$ Como el que regula la nulidad como remedio previsto por el tribunal de apelación (10 de febrero de 1838), la competencia para el juzgamiento de serenos (19 de febrero de 1838), el reconocimiento de documentos presentados en juicio ( 4 de abril de 1838), notificaciones de pago ( 2 de mayo de 1838), dictamen fiscal (3 de mayo de 1838), ejecución de sentencias ( 9 de mayo de 1838) y deposiciones de jueces subalternos (25 julio de 1838). BLOD, cit. (n. 47), pp. 8, 25, 35, 36, 37 y 55 .

${ }^{58}$ Como el que crea el Liceo de San Felipe ( 5 de junio 1838), el cargo de director general de obras públicas (20 de noviembre de 1838), la Universidad de Chile y extingue a la Universidad de San Felipe (17 de abril de 1839) y el que regula la Contaduría Mayor y el Tribunal Superior de Cuentas (18 de mayo de 1839). BLOD., cit. (n. 47), pp. 45, 86, 129 y 153. 
blecen penas ${ }^{59}$, o hacen excepción al pago de tributos ${ }^{60}$, materias todas que en el presente serían consideradas como propias de ley. En otros casos complementa o modifica leyes sin referencia a facultades extraordinarias o llama "lei" a decretos dictados sin fundamento en dichas facultades ${ }^{61}$. A la inversa, varios decretos dictados con fundamento explícito en el uso de facultades extraordinarias, regulan cuestiones meramente reglamentarias o sólo contienen decisiones particulares de ejecución ${ }^{62}$. En fin, categoría normativa y contenidos no siempre se unieron, en el siglo XIX, de modo consistente y en armonía con la naturaleza de las reglas concernidas.

Como sea, de los decretos que en lo formal merecen el reconocimiento como legislativos, más de la mitad fueron aprobados en 1837 (treinta y seis), diecinueve en 1838 y sólo trece en 1839 (que sólo cubre hasta el 31 de mayo). En lo que respecta a su materia, el mayor número de decretos legislativos tiene relación directa con la jurisdicción (cuestiones orgánicas y procesales), alcanzando al menos dieciséis decretos. Le sigue hacienda con catorce decretos, los que incluyen cuestiones generales como tributos, diezmos o deuda interna, o particulares, como concesiones a particulares. En materia penal pueden incluirse doce decretos y seis en cuestiones militares. Los restantes se dividen en asuntos heterogéneos ${ }^{63}$.

Sin duda, los decretos con mayor propiedad pueden considerarse legislativos son los que se aprueban en 1837 en materias jurisdiccionales. La explicación de este hecho es sencilla, pues ellos se escindieron del proyecto de Código de Procedimiento Civil redactado por Mariano Egaña, quien en 1837 se desempeñó como ministro de Justicia del General Joaquín Prieto ${ }^{64}$. De los 963 artículos del

59 Tanto la regulación sobre animales aparecidos ( 9 de marzo de 1837) como la de bombas de incendio (1 enero de 1839), contienen penas. BLOD., cit. (n. 44), p. 163 y BLOD., cit. (n. 47), p. 97.

${ }^{60}$ Como el decreto de 7 de marzo de 1839 sobre diezmos y primicias. BLOD., cit. (n. 47), p. 118.

${ }^{61}$ Sin referencia a facultades extraordinarias, el decreto de 27 de noviembre de 1837 complementa la ley sobre suplentes de los tribunales (llamada así por el decreto, pero que es otro decreto fundado en facultades extraordinarias); el de 20 de junio de 1838 modifica la ley de 2 de agosto de 1832 sobre orden de precedencia; y el de 24 de mayo de 1839 restablece la vigencia de una disposición de la ley de Indias. El decreto de 14 de marzo de 1839 señala en su texto que "modifica la lei del 20 de noviembre de 1838": ni el decreto modificatorio ni el texto del 20 de noviembre invocan facultades extraordinarias. El decreto de 14 de agosto de 1838 regula la expropiación pese a que la Constitución encarga la materia a la ley. No cita facultades extraordinarias. BLOD., cit. (n. 44), p. 201; BLOD., cit. (n. 49), pp. 51, 64, 117 y 144.

${ }^{62}$ Desde un punto de vista que asume los criterios del derecho administrativo contemporáneo. Por ejemplo, el reglamento para el gremio de los jornaleros de Valparaíso (21 de abril de 1837), los que otorgan una concesión para la navegación por vapor (20 de octubre de 1837 y otro de 27 de diciembre de 1838), y en que otorga una concesión de agua potable en Coquimbo (30 de marzo de 1838). BLOD., cit. (n. 44), pp. 154 y 206; y BLOD., cit. (n. 47), pp. 18 y 107.

${ }^{63}$ Tales como organización de los ministerios, reglas de sucesión intestada, cuentas y organización de la contabilidad fiscal.

${ }^{64}$ La primera parte de este proyecto fue publicada y dada a conocer al Congreso en agosto de 1835. Ella se destinaba a la "administración de justicia en materia civil" y formaba parte de un código con tres secciones. Mariano Egaña hacia 1840 todavía no terminaba las restantes dos. Es pertinente notar que ya en 1835 el ministro del Interior Joaquín Tocornal propuso emprender 
proyecto inicial de Egaña, 239 se encuentran en cuatro decretos con fuerza de ley dictados bajo la autoridad de las facultades extraordinarias otorgadas en 1837: el de implicancias y recusaciones ${ }^{65}$, el de fundamentación de las sentencias ${ }^{66}$, el de juicio ejecutivo y concurso de acreedores ${ }^{67}$; y el de recurso de nulidad ${ }^{68}$. Las denominadas leyes marianas también incluyen integración de las Cortes, subrogación y suplencia de los jueces, tacha de testigos, abogados, empate de votos en causas criminales, juzgados de minería, provisión de cargos judiciales, causas de mayor cuantía, tribunal de cuentas, consulado, etcétera.

Como se indicó antes, muy pocos decretos extraordinarios regularon lo propiamente atingente a la guerra con Perú, conmoción interior o amenaza de conmoción interior. El listado de decretos asociados a las excepcionalidad que justifica las facultades extraordinarias es más bien breve y de disposiciones particulares $^{69}$. Quizás el más ajustado al fundamento de la excepción sea el dictado un día después de la concesión de las facultades extraordinarias, el 2 de febrero de 1837, que creó los consejo de guerra permanentes, previstos para el juzgamiento de los delitos de traición, sedición, tumulto, motín, conspiración contra el orden público, contra la Constitución o el gobierno ${ }^{70}$. En rigor, decretos de este tipo

en esta materia un proceso de codificación parcial, precisamente, en consideración al tiempo que tardaría el Congreso en aprobar un cuerpo legal extenso y a la necesidad de contar con una única ley que se pusiese en práctica al mismo tiempo. Bravo LIRA, Bernardino, Los comienzos de la codificación en Chile: la codificación procesal, en Revista Chilena de Historia del Derecho, 9 (Santiago, 1983), pp. 192, 193, 197.

${ }^{65}$ Este decreto de 2 de febrero de 1837 fue aclarado, modificado y adicionado posteriormente. $B L O D$., cit. (n. 44), p. 105.

${ }^{66}$ Este decreto, también de 2 de febrero de 1837, fue objeto de una consulta posterior a la Corte Suprema de Justicia. Su fiscal, el mismo Mariano Egaña, emitió un dictamen al que se le otorgó fuerza de ley: "Decreto que confiere fuerza de ley a la vista del fiscal" (10 de marzo de 1837). BLOD., cit. (n. 44), p. 101.

${ }^{67}$ De 8 de febrero de 1837.

68 De $1^{\circ}$ de marzo de 1837. Bravo Lira, Bernardino, cit. (n. 64), p. 207.

69 Pueden citarse los decretos que fijan derechos de internación especiales mientras dura la guerra (29 de julio de 1837), declaran la guerra (17 de octubre de 1838), reajustan los grados a los vencedores de Yungay (28 de marzo de 1839), autorizan a recibir condecoraciones del nuevo gobierno peruano (2 de abril de 1839), regulan el impuesto al azúcar y chancaca peruanas (13 y 17 de abril de 1839) y los que rehabilitan a militares derrotados en la revolución de 1830 (20 y 31 de mayo de 1839). BLOD., cit. (n. 44), p. 194; y BLOD., cit. (n. 47), pp. 46, 123, 132, $133,134,175$ y 177.

70 Villalobos R., Sergio, cit. (n. 42), p. 181. Collier sostiene que esta ley "no fue mayormente utilizada". No obstante lo anterior, es claro que los pocos casos en que tuvo aplicación fueron alimento relevante para la situación política que puso fin al gobierno de Portales. Como sea, dicho Consejo, formado en cada capital de provincia, estaba integrado por el juez de letras de la provincia y dos individuos nombrados por el gobierno. Contra sus sentencias no procedía apelación, ni revisión. El único recurso admisible era por la responsabilidad personal de los jueces por su sentencia y por retardo en el juzgamiento. Salazar entiende que la negación explícita de todo recurso tiene su origen en la experiencia derivada de un decreto de noviembre de 1836 que disponía que las sentencias debían ser aprobadas por una corte marcial integrada por ministros de cortes de apelación. Estos jueces actuaban con plazos distintos a la urgencia del gobierno y respetando la ley penal, lo que no convenía a los intereses del Poder Ejecutivo. Dicho decreto fue modificado posteriormente por decreto del 28 de agosto de 1837 . El 10 de julio 
son más bien la excepción en el conjunto de actos dictados en uso de facultades extraordinarias ${ }^{71}$.

En el examen general de la primera experiencia institucional chilena en que el Presidente ejerce facultades legislativas conferidas por el Congreso Nacional es posible anotar varias cuestiones. La primera es que el contexto en que estas facultades legislativas son utilizadas es anormal en lo interno y en lo internacional, lo que probablemente tiene incidencia significativa en el esporádico y débil funcionamiento del Congreso Nacional en el período comprendido entre febrero de 1837 y mayo de 1839. En este sentido, el Presidente de la República no legisla a la par con el Congreso, sino que más bien es quien asume toda la tarea de producción legislativa en este período histórico anormal. Restablecida la convivencia política ordinaria, las facultades conferidas al Presidente en 1837 parecieron inadecuadas. Prueba de ello es que el 15 de junio de 1840 Melchor de Santiago Concha propuso en la Cámara que se fijase con exactitud del término de dichas facultades (días, meses o años), que ellas no comprendían la facultad de legislar ni la de crear juzgados de cualquier naturaleza, y que los decretos tuviesen vigencia provisoria, sólo durante la extensión de las facultades extraordinarias ${ }^{72}$.

Lo segundo es que el ejercicio de esta potestad legislativa no parece responder a un plan político o programa de gobierno preestablecido. La coyuntura política asociada a los intereses políticos y jurídicos de Mariano Egaña parece inspirar una buena parte de los decretos de contenido legislativo de esta etapa histórica, sin que pueda comprobarse un propósito más general como la reforma del Estado o la construcción de un ordenamiento jurídico patrio que sustituya las normas coloniales todavía en vigor. El valor circunstancial de los decretos legislativos resulta ratificado por la moción del diputado presbítero Rafael Valdivieso, quien en 1840 propuso que las leyes dictadas en uso de facultades extraordinarias debían someterse a revisión y sanción del Congreso para que produjeran efectos permanentes y se tuviesen por "verdaderas leyes" 73 . Sin embargo, la utilidad de la legislación delegada para la expedición y brevedad de los procesos sirvió de defensa natural para sustentar su vigencia permanente ${ }^{74}$.

de 1839 (diez días después de extinguidas las facultades extraordinarias), el Presidente propuso la supresión de estos consejos, lo que fue aprobado en agosto del mismo año por el Congreso Nacional. Collier, Simon, La construcción de una república. 1830-1865. Politica e ideas (Santiago, Ediciones Universidad Católica de Chile, 2005), p. 93; Encina, Francisco A., Historia de Chile (Santiago, Editorial Ercilla, 1984), XXII, p. 66; SALAZAR, Gabriel, cit. (n. 46), pp. 399 y 400.

${ }^{71}$ Encina sostiene que tanto el Presidente Prieto como su ministro Tocornal "habían procurado usar de las facultades extraordinarias en la gestión política interior lo menos posible". Según este historiador ambos sólo esperaban el término de la guerra para dimitir los poderes que el Congreso otorgó. EnCINA, Francisco, cit. (n. 70), p. 65.

72 Letelier, Valentín, SCL., Cámara de Diputados: 1840-1841 (Santiago, Imprenta Cervantes, 1903), XXVII, pp. 65 y 66.

${ }^{73}$ EnCINA, Francisco, cit. (n. 70), p. 104.

${ }^{74}$ Dicha propuesta fue rechazada en definitiva el 14 de agosto de 1840 por 23 (o 22 votos según Donoso) contra 12. De todos modos se formó una comisión para que propusiese las reformas que estimare pertinentes. No hubo propuesta y, por lo mismo, las leyes marianas mantuvieron su vigencia. ENCINA, Francisco, cit. (n. 70), pp. 104 y 105. 
En tercer y último lugar, la ausencia de un contrapeso parlamentario efectivo parece haber relativizado la importancia política de otorgar al Presidente de la República una potestad legislativa delegada. En este sentido, el ejercicio de facultades legislativas extraordinarias no parece ceñirse, en todos los casos, a un criterio de necesidad. Así, encontramos decretos ordinarios con contenidos equivalentes a los decretos legislativos extraordinarios que no se fundamentan en tales facultades, lo que sugiere que los segundos no requerían de una potestad extraordinaria. Una parte no menor de las normas aprobadas bajo el amparo de estas facultades, en los hechos, contienen decisiones particulares de ejecución que podrían haberse adoptado sin acudir a potestades extraordinarias. Como sea, al no existir un Congreso Nacional activo en la fiscalización del ejercicio de las potestades extraordinarias, puede suponerse que la cuestión de su utilización o no utilización no constituía una decisión de especial relevancia política. Asunto distinto es que el transcurso de los años fuese alimento para construir una mirada crítica sobre estas leyes marianas, mirada que formó parte de los argumentos que justificaron la valoración de esta parte del período de gobierno conservador como autoritario o dictatorial.

\section{LAS LEYES DE FACULTADES EXTRAORDINARIAS Y SU PRÁCTICA. SEgUNDO PERÍ́DO (1840-1861)}

En la década 1840-1850 el Congreso Nacional no estimó necesario conferirle facultades extraordinarias al Presidente de la República. El estado de relativa paz política en lo interno y la ausencia de alguna amenaza militar externa importante permitieron el funcionamiento regular del régimen constitucional. Las facultades extraordinarias reaparecieron en 1851, en los últimos días del mandato presidencial de Manuel Bulnes.

La primera de ellas es del 14 de setiembre de 1851, aprobada cuatro días antes que asumiese la presidencia Manuel Montt Torres. A diferencia de las facultades otorgadas en 1837, esta ley detallaba las atribuciones especiales otorgadas al Presidente de la República: arrestar y trasladar personas de un punto a otro de la República, aumentar la fuerza del ejército permanente, invertir caudales públicos sin sujeción al presupuesto, remover a empleados públicos de oficina sin sujetarse al número 10 del artículo 82 de la Constitución ${ }^{75}$. Asimismo, las otorgaba por un plazo de un año, en cumplimiento de la exigencia constitucional. El Congreso, dominado por una mayoría conservadora, no otorgó al Presidente de la República facultades para dictar normas de rango legal ${ }^{76}$. Cabe notar que desde 1849 se plan-

75 BLODG. (Santiago de Chile, Imprenta de Julio Belin i Ca., 1851), XIX, pp. 495 y 496. La destitución autorizada es sin acuerdo del Senado o de la Comisión Conservadora (jefes de oficina o empleados superiores) o, en su caso, de su respectivo jefe (empleados subalternos).

76 El Presidente tampoco intentó utilizarlas en esta materia, aparentemente. En los boletines respectivos, los decretos publicados que se fundan en facultades extraordinarias son sólo cuatro. Tres de ellos crean y organizan tres batallones y un regimiento. El cuarto ordena la construcción de un vapor de guerra en Londres. No obstante lo anterior, hay dos decretos de especial relevancia jurídica y política que no invocan facultades extraordinarias, pero que regulan 
teó la reforma del numeral 6 del artículo 36 -por el precedente de 1837-, por lo que no parece extraño que el Congreso Nacional, para silenciar a los reformistas, haya tenido desde 1851 especial cuidado en detallar las atribuciones entregadas, en cumplimiento del mandato constitucional ${ }^{77}$.

Esta ley de facultades extraordinarias permitió al Presidente Montt detener y deportar a líderes políticos pertenecientes a la oposición como Arcos, Bilbao, Lastarria y Vicuña Mackenna. Varios de ellos tendrían una importante participación en la reforma constitucional de 1874 , en la que, precisamente, se promovió la eliminación de la facultad del Congreso de conferir facultades extraordinarias al Presidente de la República.

La segunda ley de facultades extraordinarias es de 15 de septiembre de 1852, aprobada un día después del vencimiento de la anterior ley ${ }^{78}$. En ella se repiten las facultades otorgadas por la ley de 1851, sin perjuicio de modificarse la atribución referida a la destitución de empleados públicos, que según la nueva norma se aplica a empleados "de toda clase" con excepción de "aquellos respecto de los cuales la Constitución previene expresamente que preceda sentencia condenatoria". Las nuevas facultades extraordinarias se otorgaron por catorce meses ${ }^{79}$. Con todo, Encina entiende que las facultades extraordinarias generaban un círculo vicioso: el gobierno no podía privarse de ellas sin exponerse a motines y ellas servían de pretexto a los revolucionarios para sus actividades ${ }^{80}$.

La tercera ley de facultades extraordinarias aprobada en la década fue la de 20 de enero de 1859. Como las anteriores, entregaba facultades al Presidente para arrestar y trasladar a cualquier punto de la República (obligando a fijar residencia $y$, si lo cree necesario, cambiarla); aumentar la fuerza del ejército permanente hasta el número que las circunstancias lo exigiesen; invertir caudales públicos sin arreglo a la ley de presupuesto ${ }^{81}$; y destituir empleados públicos sin sujeción a las formalidades del número 10 del artículo 82 de la Constitución ${ }^{82}$. Estas facultades se concedieron por un año.

asuntos de naturaleza legal. El primero de 9 marzo 1852 que regula la aplicación de sentencias de Consejos de Guerra ordinarios recaídas en delitos de sedición, motín o tumulto y el segundo sobre fuerza del Ejército permanente. BLODG., cit. (n. 75), pp. 540-543; y BLODG. (Santiago de Chile, Imprenta de Julio Belin i Ca., 1852), XX, pp. 38, 39, 47 a 55, 85.

77 Jorge Huneeus sostuvo que el numeral 6 del artículo 36 "se aplicó de una manera singularmente monstruosa" y por ello fue necesario reformarlo. Dicha reforma se reclamó desde 1849. HunEEus, Jorge, cit. (n. 14), p. 178.

${ }^{78}$ BLODG., cit. (n. 76), pp. 185 y 186.

79 Según Encina, Varas las pidió por un año más, no para utilizarlas, sino que para intimidar a algunos revolucionarios y para apaciguar a los partidos favorables al orden. El Congreso fue más allá y concedió las facultades por catorce meses y además aprobó una moción que declaraba nulo el pacto de Purapel y autorizaba a dar de baja a los militares que apoyaron la revolución. Encina, Francisco A., Historia de Chile (Santiago, Editorial Ercilla, 1984), XXV, p. 99.

${ }^{80}$ Ibíd., p. 101.

${ }^{81}$ Debemos notar que en un momento en el que el Presidente gozaba de esta facultad extraordinaria, el Congreso Nacional aprobó leyes que autorizan gastos excepcionales, tales como los de la legación a Roma (3 de noviembre de 1860) y el suplemento de partida para el Ministerio de Relaciones Exteriores (de la misma fecha). BLODG., cit. (n. 26), pp. 285 y 286.

${ }^{82}$ No hay referencias en el Boletín al uso de facultades extraordinarias. Con todo, los decretos 
En 1 de octubre de 1859 el Congreso Nacional prorrogó hasta el 1 de noviembre de 1860 las facultades concedidas el 20 de enero ${ }^{83}$. El 23 de octubre de 1860, poco antes del vencimiento del plazo anterior, el Congreso Nacional autorizó al Presidente a mantener en vigor y hacer efectiva las medidas ya adoptadas, hasta el 30 de septiembre de $1861^{84}$.

\section{Actividad normativa general del Presidente de la República en el período}

Como ha quedado dicho, en el período 1840-1861, si bien el Presidente dispuso de facultades extraordinarias, éstas no se otorgaron ni interpretaron como fuente de una competencia legislativa general para el Presidente. Más bien, en los casos indicados en el epígrafe precedente, las facultades extraordinarias fueron empleadas para adoptar medidas y sanciones de naturaleza penal contra minorías políticas. El abandono de esta potestad presidencial para aprobar normas generales de nivel legal, permite elaborar dos hipótesis excluyentes para el período indicado: hay un cambio político significativo que impide al Presidente aprobar disposiciones con tal carácter o, más bien, el Poder Ejecutivo emplea otras herramientas para contar con la regulación que requiere para realizar su actividad política, cualesquiera sea su rango normativo. Los antecedentes existentes sugieren que en el período 1840-1861, el Presidente más que renunciar a toda potestad legislativa extraordinaria, utilizó otras vías para lograr los resultados normativos buscados.

Cabe aquí distinguir tres áreas: conservación del orden público interior, creación de un ordenamiento jurídico patrio en materias en que la regulación hispánica quedó obsoleta y organización de la administración y servicios públicos. En su conjunto, los cambios acaecidos en estos ámbitos permitieron prescindir de las facultades extraordinarias legislativas tal como las interpretó Mariano Egaña.

En lo que dice relación con la conservación del orden público, la Constitución además de las facultades extraordinarias contaba con el régimen de estado de sitio, que en los hechos, aparentemente, fue suficiente para adoptar las medidas necesarias para enfrentar alzamientos y rebeliones. El estado de sitio permitía, conforme con el artículo 161 suspender el imperio de la Constitución. En el período 18331874, esta declaración se utilizó en cinco oportunidades para dominar situaciones difíciles de alteración del orden público interior ${ }^{85}$. Algunos críticos como Lastarria, afirman que el Presidente no sólo suspendió garantías individuales (para lo que

que cierran los puertos de Caldera, Huasco y Carrizal Bajo (del 14 enero 1859) indican el "uso de las facultades de que estoi investido". Cierres posteriores de puertos y su reapertura se realizan sin referencia dichas facultades (Concepción, Atacama, Coquimbo). BLODG. (Santiago de Chile, Imprenta Nacional, 1859), XXVII, pp. 10, 28, 29, 38, 39, 46 y 47.

${ }^{83} B L O D G$., cit. (n. 26), p. 135. Podemos observar que, con esta última ley, el gobierno de Montt completó cerca de cinco años con facultades extraordinarias, de los diez que estuvo en el poder.

${ }^{84}$ Ibíd., pp. 274 y 275 . El tenor de esta autorización indica que sólo se faculta al Presidente para mantener la vigencia de las medidas ya adoptadas, pero no a adoptar nuevas medidas. Según la misma autorización, de otro modo, las acciones aprobadas debían cesar en sus efectos el 1 de noviembre de 1860 .

85 En la provincia de Santiago el 10 de febrero de 1840; en la misma provincia, por ochenta y cinco días el 8 de marzo de 1846; en las provincias de Santiago y Aconcagua, por sesenta días, 
estaba habilitado), sino que suspendió todo el orden político, arrogándose todo el poder del estado, sin importar las reglas de la Constitución ${ }^{86}$. En la misma línea crítica se sostiene que el Presidente, en uso de los poderes otorgados en estado de sitio, menoscabó la independencia del Congreso, aprisionando o desterrando a alguno de sus miembros ${ }^{87}$.

Si se intenta comparar estado de sitio y facultades extraordinarias, la única medida previa a 1840 que tuvo fundamento en estas últimas y que no se volvió a utilizar fue la crear consejos de guerra permanente facultados para aplicar la pena de muerte. Las restantes penas, cuando fue necesario emplearlas para reprimir alteraciones del orden interno, pudieron aplicarse conforme con las facultades propias del estado de sitio o con el procedimiento ordinario ${ }^{88}$.

Puede observarse, además, que en 1844 se aprobó la ley de régimen interior y en 1846 la ley de imprenta, las que asentaban y robustecían las facultades del Poder Ejecutivo.

\section{La codificación en el periodo}

La fuerza de los hechos demostró que el Congreso Nacional no ofrecía las condiciones adecuadas para emprender la elaboración y aprobación la creación de los cuerpos legales extensos y sistemáticos necesarios para reemplazar el ordenamiento jurídico heredado del reinado Borbón. Por lo mismo, se organizaron comisiones y mandatos codificadores, con el propósito de reducir la intervención parlamentaria a una revisión de textos ya elaborados.

A partir de 1840, el Congreso Nacional desarrolló un nuevo procedimiento para la elaboración de códigos ${ }^{89}$. Este responde, en parte, al debate sobre la necesidad de crear un ordenamiento jurídico chileno propio, en especial por las

el 7 de noviembre de 1850; y por cuarenta días, en las provincias de Santiago y Valparaíso, el 20 de abril de 1851. RoldÁn, Alcibíades, cit. (n. 16), p. 434.

${ }^{86}$ Sin perjuicio de que, en algunos casos, ciertas actuaciones jurídicas dicen lo contrario. Así, por ejemplo, el mismo día de la declaración de estado de sitio del 8 de marzo de 1846, un decreto declaró en vigencia todas las prescripciones constitucionales y leyes electorales. La principal crítica de Lastarria se dirigió, como la de tantos otros, a la creación de un consejo de guerra permanente, que somete "la vida y honra de los chilenos al arbitrio de tres empleados del gobierno". Lastarria, José Victorino, La Constitución Política de la República de Chile comentada (Valparaíso, Imprenta del Comercio, 1856), pp. 58, 59.

${ }^{87}$ En virtud del estado de sitio del 8 de marzo de 1846, se relegó a cuatro personas a Chiloé y se desterró a otras cuatro al extranjero.

${ }^{88}$ Por ejemplo, la proclama publicada el 11 de diciembre de 1858 que convocaba a una asamblea constituyente (firmada, entre otros, por Ángel Custodio Gallo, Manuel Antonio Matta, Guillermo Matta, Benjamín Vicuña Mackenna e Isidoro Errázuriz) fue perseguida por la vía ordinaria como delito de sedición. La Corte Suprema, en definitiva, condenó a ciento cincuenta y siete convocantes a la pena de destierro por un año. Encina, Francisco, cit. (n. 79), p. 187.

${ }^{89} \mathrm{La}$ idea de nacionalizar y perfeccionar el ordenamiento jurídico chileno mediante códigos, por cierto, es anterior. Portales ya constató los problemas de la legislación patria a comienzos de la década del treinta. En dos oficios suscritos por el gobierno (redactados por Juan y Mariano Egaña) se propuso al Senado autorizar a un individuo para elaborar un código de leyes comprensivo de los principales ramos administrativos y de la organización económica de los poderes nacionales. GuZMÁn Brito, Alejandro, Portales y el Derecho (Santiago, Editorial Universitaria, 1988), pp. 73-81. 
dificultades y dudas de interpretación que generaban las numerosas fuentes del derecho españolas que mantenían su vigencia. En esta línea, fue el propio senador Egaña quien promovió una reforma completa del ordenamiento jurídico chileno en lo sustantivo y procedimental ${ }^{90}$. Con este propósito, el ministro Tocornal, como vicepresidente de la República, señalaba al Congreso Nacional en la sesión del 1 de junio de 1840 que "objetos de una trascendencia primaria reclaman la acción organizadora del Poder Legislativo” y que la propia Constitución fijaba un programa legislativo urgente ${ }^{91}$.

En este contexto, la opción de elaborar códigos era atractiva, pero se temía que su discusión parlamentaria hiciese muy lenta e inefectiva su tramitación y aprobación. La experiencia del propio Egaña y su proyecto de código de procedimientos daban cuenta de lo inadecuado del trámite legislativo ordinario para lograr la aprobación de cuerpos legales extensos y sistemáticos ${ }^{92}$. Conviene subrayar, además, que parte importante de la legislación hispánica vigente, formaba parte de compilaciones o textos sistematizados y concordados.

El 10 de agosto de 1840 Andrés Bello propuso la creación de una comisión integrada por dos senadores y tres diputados para preparar la codificación de las leyes civiles, en razón de las dudas que generaba el derecho vigente. Dicha comisión se aprobó, pero su funcionamiento no fue adecuado ${ }^{93}$. Fue necesario modificar el método de trabajo: Bello redactaría, su trabajo sería publicado por la prensa y luego, una junta revisora del proyecto de Código Civil informaría periódicamente del avance del proyecto a las dos cámaras ${ }^{94}$.

90 Encina, Francisco, cit. (n. 70), p. 105.

91 Programa que, en parte, se cumplió. Letelier, Valentín, SCL. (Santiago, Imprenta Cervantes, 1906), XXVIII, p. 243. El artículo 2 transitorio de la Carta de 1833 indicaba que para "hacer efectiva esta Constitución" debiesen dictarse con preferencia las siguientes leyes: general de elecciones; de arreglo de régimen interior; de organización de los tribunales y administración de justicia; la del tiempo en que los ciudadanos deben servir en las milicias y en el ejército, y la de reemplazos; y el plan general de educación pública. El Araucano del 22 de octubre de 1841 sostiene que este orden se ha respetado en la presentación a las Cámaras o redacción de los respectivos proyectos, lo que es una verdad a medias. LeTELIER, Valentín, SCL. (Santiago, Imprenta Cervantes, 1906), XXIX, p. 395.

92 El camino que debía seguir la codificación, en todo caso, era discutido. En El Araucano de 6 de diciembre de 1839 se proponía comenzar con las normas existentes para después introducir las correcciones y progresos necesarios. LETELIER, Valentín, SCL. (Santiago, Imprenta Cervantes, 1906), XXVIII, p. 354.

93 Comisión que recibió el encargo de elaborar un cuerpo ordenado y completo de legislación civil, descartando lo superfluo o lo que pugne con las instituciones de la República y dirimiendo los puntos controvertidos. Esta comisión quedó integrada por los senadores Bello y Egaña, y los diputados Irarrázaval, Cobo y Vial; ENCINA, Francisco, cit. (n. 70), p. 105. La comisión se instaló el 11 de septiembre de 1840 . Su programa de dos sesiones al mes, para corregir y simplificar los modelos existentes, no se cumplió. Su avance fue lento. Como dice un informe de la época, "un sólo artículo ha dado a veces materia para muchas horas de discusión”. LETELIER, Valentín, SCL. (Santiago, Imprenta Cervantes, 1906), XXIX, p. 271.

${ }^{94} \mathrm{La}$ junta revisora quedó compuesta de tres individuos elegidos por la Cámara de Diputados y dos por el Senado. Ante el retardo de las cámaras en nombrarlos, el Presidente de la República tuvo que insistir en noviembre de 1841 para que ellos fuesen nombrados. En septiembre de 1842 el Senado todavía no había nombrado a sus representantes. En julio de 1845 se reunieron en 
La modalidad de trabajo adoptada no resultó especialmente expedita y, por lo mismo, se plantearon algunas alternativas como comisiones mixtas o la concesión de facultades al Presidente de la República, las que no prosperaron ${ }^{95}$. Como sea, recién en la década de los cincuenta, el trabajo de Bello estuvo en condiciones que permitían su aprobación, lo que impulsó nuevamente el interés político en la codificación ${ }^{96}$. Así, el mismo día en que venció la Ley de facultades extraordinarias de 1851, el Congreso Nacional aprobó una ley que facultaba al Presidente de la República para designar personas encargadas de redactar proyectos de códigos y asignarles una renta igual a la de ministros de la Corte Suprema ${ }^{97}$. La misma ley dispuso que el proyecto revisado por la comisión especial sería sometido por el Presidente al Congreso Nacional. Del avance del trabajo debía darse cuenta anual al propio Congreso. Por Ley del 26 octubre 1852, se designó como responsable del Código de Procedimientos Civiles a Andrés Bello, del Código Penal a Antonio García Reyes y se creó una comisión para revisar el trabajo encomendado por ley de 10 setiembre de 1840 para elaborar el Código Civil ${ }^{98}$.

Pese a que el camino seguido por el Congreso de nombrar comisiones y designar redactores especializados no fue en todos los casos exitoso como instrumento expedito para adaptar la legislación española vigente a la nueva realidad política, es claro que su existencia disminuyó la necesidad de emplear las facultades extraordinarias como sustento de reformas o iniciativas legislativas extensas y complejas, como las introducidas por Egaña al procedimiento civil en el año $1837^{99}$. Esta nueva forma de progresar en la construcción de un ordenamiento jurídico patrio,

un solo cuerpo la comisión de legislación del Congreso Nacional y la junta revisora. LETELIER, Valentín, SCL. (Santiago, Imprenta Cervantes, 1906), XXIX, pp. 305, 400, 407, 412, 415, 418; y de Él MISMO, SCL. (Santiago, Imprenta Cervantes, 1905), XXX, pp. 16, 24, 25, 27, 129 y 240; SCL. (Santiago, Imprenta Cervantes, 1908), XXXI, p. 126; SCL. (Santiago, Imprenta Cervantes, 1908), XXXVII, p. 96.

95 Recordemos que el Código Civil fue aprobado en diciembre de 1855, quince años después de la primera iniciativa para su creación. En El Araucano de 22 de octubre de 1841 se propone dar un plazo al gobierno para que aporte su experiencia en el proyecto de la ley de régimen interior. También se sugieren otros expedientes para ahorrar tiempo y trabajo: crear comisiones mixtas de ambas cámaras o permitir la vigencia de leyes cuyas correcciones surjan “al tiempo y la experiencia”, evitando así discusiones áridas y puramente teóricas de la mayor parte de los legisladores. El mismo texto alaba la amplia facultad entregada al Presidente por una ley de 1835 para fomentar la construcción de caminos, canales y puentes. LETELIER, Valentín, SCL. (Santiago, Imprenta Cervantes, 1906), XXIX, p. 397. Civil.

${ }^{96}$ En octubre de 1852, Andrés Bello entregó al gobierno un proyecto completo de Código

${ }^{97}$ Lei de 14 de septiembre de 1852. Según esta ley el Presidente podía proponer un premio para el autor del proyecto. BLODG., cit. (n. 76), pp. 191, 192.

${ }^{98}$ BLODG., cit. (n. 76), pp. 241-243.

${ }^{99}$ El proceso de elaboración y aprobación del Código Civil sólo culminó en 1855. El Código Penal entró en vigor en 1874 y el de Comercio en 1865. La ley de organización y atribuciones de los tribunales fue aprobada en 1875 y la de procedimiento civil en 1902. Encina señala que Egaña ya tenía su proyecto de procedimiento civil y orgánico listo a mediados del siglo XIX, pero se estrelló “contra la inercia y rutina” de los órganos políticos de entonces. Egaña también elaboró un proyecto de ley de imprenta que fue utilizado para el texto que en definitiva se aprobó. EnCINA, Francisco, cit. (n. 70), p. 105. 
por lo demás, se afianzó en un momento histórico en que una ley de facultades extraordinarias como la de 31 de enero de 1837 era impensable para las fuerzas políticas dominantes.

\section{LA REFORMA CONSTITUCIONAL DE 1874}

Las facultades extraordinarias dejaron de otorgarse una vez concluido el mandato del presidente Montt. Su utilidad disminuyó en las nuevas condiciones en que se desarrolló la política chilena y hacia 1874 ya eran "un trasto viejo abandonado en el desván" 100 .

Sin embargo, el decaer práctico de las leyes de facultades extraordinarias no disminuyó las críticas que generaba su existencia. Dichas críticas formaron parte de los argumentos que inspiraron la reforma constitucional de 1874. En particular se reprochaba la concentración ilimitada del poder público en el Presidente de la República generada por la ley de facultades extraordinarias de 31 de enero de 1837 y sostenía que la propia aprobación de estas facultades alimentaba conspiraciones, motines y revueltas ${ }^{101}$. No debe dejar de observarse, además, que algunas de las personas afectadas directa o indirectamente por medidas adoptadas en uso de facultades extraordinarias, hacia el último cuarto del siglo XIX, formaban parte del gobierno o el Congreso Nacional, por lo que no es raro que la reforma del numeral 6 fuese celebrada de modo especial.

Parte de la crítica recayó en el uso de las facultades extraordinarias por parte del Presidente de la República para la aprobación de decretos legislativos. Así, el diputado Manuel Antonio Tocornal, en julio de 1857, sostuvo en la Cámara que "el poder legislativo no es delegable bajo la forma de facultades extraordinarias especiales, sino en circunstancias extraordinarias especiales, y cuando así lo exija la conservación del orden público. La delegación del poder legislativo en fuerza de cualquiera otra razón, es inconstitucional"102. Cabe notar que Tocornal todavía aceptaba que la facultad de legislar puede emplearse como instrumento en situaciones de excepción, idea que si bien Huneeus compartía, parece ir en paulatina retirada en el constitucionalismo chileno de la segunda mitad del siglo XIX.

Con todo, la reforma de 1874 fue precedida por un conjunto de proyectos de reforma dirigidos a disminuir o regular el poder presidencial. Pueden citarse entre ellos los de Federico Errázuriz (1850), Lastarria y Santa María (1858), Melchor de Santiago Concha (1860), Ricardo Claro (1864), Melchor de Santiago Concha (1864), Pedro Félix Vicuña (1864), Federico Errázuriz (1870) y Melchor de Santiago Concha $(1870)^{103}$. En estos proyectos, las facultades extraordinarias estaban,

${ }^{100}$ Encina, Francisco A., Historia de Chile (Santiago, Editorial Ercilla, 1984), XXIX, p. 113.

101 Encina critica este argumento que invierte la secuencia de los hechos: primero existen motines, conspiraciones y revueltas, y luego se conceden facultades extraordinarias, y no al revés. Ibíd.

${ }^{102}$ Huneeus, Jorge, cit. (n. 14), p. 179.

103 Donoso, Ricardo, Las ideas politicas en Chile (3ra. Edición, Buenos Aires, Editorial Universitaria de Buenos Aires, 1975), pp. 377-390, 390-396. Notemos, en todo caso, que ya en 1849 los diputados Bruno Larraín y José Victorino Lastarria presentaron mociones 
casi siempre, en el centro de las críticas al autoritarismo presidencial, aunque no necesariamente en su faz legislativa. En el proyecto de 1860, Melchor de Santiago Concha decía que "el sistema de gobierno que nos rige [...] ha tenido que marchar desde treinta años a esta parte, entre facultades extraordinarias, declaraciones de sitio, sangre y lágrimas " 104 . Por lo mismo, en septiembre de 1868, el programa del Club de la Reforma de Copiapó, proponía, en vísperas de elecciones parlamentarias, la reglamentación de las facultades extraordinarias y los estados de sitio $^{105}$. En fin, José Nicolás Hurtado, en su discurso de incorporación como académico de la Facultad de Leyes y Ciencias Políticas de la Universidad de Chile pronunciado el 18 de diciembre de 1870, afirmaba que la seguridad y libertad personales se encontraban permanentemente amenazadas por las facultades extraordinarias ${ }^{106}$.

La reforma constitucional de 1874 fue fruto de una iniciativa que comenzó con la aprobación de la ley de reformabilidad de 28 de agosto de 1867 y tuvo como propósito principal disminuir las facultades del Poder Ejecutivo y aumentar las del Congreso Nacional ${ }^{107}$. Varias de las reformas introducidas a las disposiciones de la Carta de 1833 fueron más bien simbólicas, toda vez que la realidad ya había ajustado su aplicación o interpretación. Como sea, la ley de 24 de octubre de 1874 modificó el artículo 36 con un nuevo numeral 6 que decía: "[inc. $\left.1^{\circ}\right]$ Dictar leyes excepcionales $i$ de duración transitoria que no podrá exceder de un año, para restrinjir la libertad personal $i$ la libertad de imprenta, i para suspender o restrinjir el ejercicio de la libertad de reunión, cuando lo reclamare la necesidad imperiosa de la defensa del Estado, de la conservación del réjimen constitucional o de la paz interior. [inc. 20] Si dichas leyes señalaren penas, su aplicación se hará siempre por los tribunales establecidos. [inc. $3^{\circ}$ ] Fuera de los casos prescritos en este inciso, ninguna lei podrá dictarse para suspender o restrinjir las libertades o derechos que asegura el artículo 12".

Esta nueva disposición constitucional impidió la delegación de potestad legislativa por medio de facultades extraordinarias, aunque permitió al propio Congreso, en los tres supuestos indicados en el inciso primero, dictar leyes excepcionales y transitorias que podían afectar los derechos mencionados por la misma norma, con los límites ahí explicitados ${ }^{108}$.

para reglamentar las facultades extraordinarias. La comisión de legislación de la Cámara de Diputados las refundió en un proyecto único de catorce artículos. En Senado fue cuestionada la constitucionalidad del proyecto y fue, en definitiva, archivado.

${ }^{104}$ Donoso, Ricardo, cit. (n. 103), p. 383. Frente a esta crítica, Barros Luco defendía la conveniencia de mantener las facultades extraordinarias por la necesidad de reunir en manos del Ejecutivo la suma de poder indispensable para la tranquilidad y la salvación de las instituciones.

${ }^{105}$ Ibíd., p. 387.

${ }^{106}$ Ibíd., p. 388.

107 El Congreso elegido en 1870 sólo alcanzó a aprobar dos de las treinta y cuatro disposiciones reformables, pues quedó entrampado en cuestiones pueriles. Por lo mismo, la tarea reformista fue asumida por el Congreso Nacional elegido en 1873.

${ }^{108}$ Huneeus, para afirmar que la nueva norma impide delegar, no lo dice directamente, sino que cita la opinión de José Clemente Fabres, Pedro Montt y Manuel Recabarren formulada en la sesión del Senado de 8 de julio de 1887. El uso de la expresión y esta cita sugieren que no existía consenso acerca de esta consecuencia directa de la reforma constitucional de 1874 después de más de diez años de su vigencia. 
La norma reformada, si bien disminuyó la posibilidad de reforzar el poder presidencial mediante facultades extraordinarias, aportó en tres cuestiones importantes para el constitucionalismo: determinó los supuestos de excepción que justifican dictar leyes excepcionales como las autorizadas (necesidad imperiosa, ineludible, de la defensa del Estado, la conservación del régimen constitucional o la paz interior); limitó los derechos que pueden afectarse y la forma de afectarlos (restringir la libertad personal y de imprenta; suspender o restringir el ejercicio de la libertad de reunión) ${ }^{109}$; impuso el deber de aplicar penas, en el caso que ellas se encontrasen previstas en la ley excepcional, por los tribunales establecidos. Sería el Congreso, y no el Presidente de la República, el competente para aprobar, mediante una ley, la regulación que serviría de respuesta ante una necesidad de gobierno de carácter excepcional. Esta ley, conviene observar, podía otorgar facultades especiales al Presidente de la República respetando las exigencias del numeral 6, pero ellas debían de pertenecer al ámbito del poder ejecutivo y no del poder legislativo.

La reforma del artículo 36 no 6 formó parte de una modificación que incluyó también el artículo 161, regulador del estado de sitio. En dicho precepto el constituyente derivado dispuso que las facultades especiales concedidas al Presidente en estado de sitio son sólo dos: arrestar a personas en sus propias casas o en lugares que no sean cárceles (ni otros que estén destinados a la detención o prisión de reos comunes); trasladar a personas de un departamento a otro de la República, dentro del continente y de los límites territoriales fijados por la Constitución. Se eliminó toda referencia a la suspensión del imperio de la Constitución, cuestión que generaba numerosas críticas ${ }^{110}$.

En opinión de Huneeus, ambas reformas (artículos 36 nº y 161) eliminaron el peligro de establecer en Chile un régimen despótico y dictatorial bajo el amparo aparente de la Constitución ${ }^{111}$. Lo cierto es que las reformas, en su conjunto, parecen no haber incidido en la introducción anticipada de un régimen parlamentarista, ni haber generado un cambio profundo en el curso de la historia. En rigor, tales cambios tuvieron lugar en la década anterior. En lo propio del ámbito de la excepcionalidad, las nuevas facultades extraordinarias y el nuevo estado de sitio no tuvieron la oportunidad de ser utilizados. Y después del 7 de enero de 1891, tanto el gobierno como los revolucionarios, optaron, simplemente, por prescindir de la Constitución.

109 Protección reforzada por el inciso final del mismo numeral 6.

110 Según Encina la suspensión del imperio de la Constitución prevista en la redacción original del artículo 161 fue sólo un "lapsus de redacción” del constituyente de 1833 . No tenía sentido que la propia Constitución declarase su abrogación por la vigencia del estado de sitio. El mismo Encina observa que "a nadie se le ocurrió dar esta inteligencia a la disposición del artículo 161 [...] menos aun aplicarla”. ENCINA, Francisco, cit. (n. 100), pp. 116 y 117.

111 Huneeus va más allá y cree que debiese suprimirse por completo el estado de sitio. HuneEus, Jorge, cit. (n. 14), p. 181. 


\section{CONSIDERACIÓN FINAL}

Del estudio realizado, es posible comprobar que la génesis de la delegación de la potestad legislativa en el derecho chileno se encuentra en un acto de excepción que transfiere potestades ilimitadas al Presidente de la República. No hay, como se explicó, una reflexión razonada acerca de la conveniencia de otorgar una potestad legislativa delegada y limitada al Presidente de la República, sino una simple habilitación competencial de carácter general que, en su indeterminación, incluyó facultades legislativas.

La ley de facultades extraordinarias del 31 de enero de 1837 fue la única que dio lugar al ejercicio de una potestad legislativa presidencial. Las posteriores leyes que otorgaron facultades extraordinarias fijaron el listado de potestades excepcionales sin incluir la potestad legislativa. Los decretos legislativos fruto de esta potestad exorbitante, con pocas excepciones, respondieron más bien a un cúmulo de circunstancias políticas coyunturales, asociadas a la persona y obra de Mariano Egaña, una guerra en curso y a un Congreso que no celebraba sesiones regulares. De todos ellos, el único que generó un reproche político persistente en el tiempo, por sus consecuencias materiales, fue el que creó consejos de guerra permanentes

Por otro lado, el ejercicio de potestad legislativa por el Presidente generó críticas y alguna duda jurídica (como la vigencia de las normas una vez concluida la excepcionalidad), pero dicho tópico no parece haber constituido una cuestión central en el debate político del período conservador. Lo anterior a diferencia de las facultades extraordinarias no legislativas, que sí fueron objeto de una discusión política extensa, tanto por sus efectos reales como simbólicos, en especial, sobre los opositores al presidencialismo instaurado por la Constitución de 1833.

En armonía con lo anterior, debe destacarse que la frontera entre potestad legislativa y potestad reglamentaria en el siglo XIX carece de la precisión técnica que adquirió en el siglo XX. Por lo mismo, la idea de u s u r p a c i ó n o i n v a s ión de los poderes propios, reconocida en el constitucionalismo contemporáneo, tiene un cariz distinto bajo el régimen constitucional de 1833 . La ausencia de una delimitación rígida y clara entre ley y reglamento explica que algunos de los encargos reglamentarios aprobados por el Congreso no siempre se ajustasen bien al campo de lo propiamente reglamentario. Esta permeabilidad del límite entre ley y reglamento en un sentido jurídico estricto, refuerza la importancia de la valoración de los parlamentarios sobre aquello que forma parte de las facultades normativas que pertenecen al Poder Ejecutivo.

La reforma constitucional de 1874, en lo que nos interesa, cerró por completo la posibilidad que el Presidente dictase lo que en el presente se denomina "decretos con fuerza de ley" bajo el amparo de facultades extraordinarias concedidas por el Congreso. Esta reforma ratificó un equilibrio político e institucional en el que el Congreso Nacional poseía una potestad legislativa que primaba de modo incuestionado sobre las facultades normativas presidenciales. Esta primacía adquirió todavía mayor valor en un contexto de un número pequeño de leyes aprobados cada año. Después de la revolución parlamentaria de 1891 la idea de delegación 
de la potestad legislativa careció de todo sentido. Esta primacía sólo se revertiría a partir de 1927.

BiBLIOGRAFÍA

Fuentes

Boletín de la leyes y de las órdenes y decretos (2a edición, Santiago de Chile, Imprenta de la Independencia, 1841), VII, VIII.

Boletín de las leyes, órdenes i decretos del Gobierno XIX, (Santiago de Chile, Imprenta de Julio Belin i Ca., 1851); XX, (Santiago de Chile, Imprenta de Julio Belin i Ca., 1852); XXVII (Santiago de Chile, Imprenta Nacional, 1859); XXVIII (Santiago de Chile, Imprenta Nacional, 1860).

Letelier, Valentín, Sesiones de los Cuerpos Lejislativos de la República de Chile, Cámara de Senadores 1836-1838 (Santiago, Imprenta Cervantes, 1903), XXV.

-- Sesiones de los Cuerpos Lejislativos de la República de Chile, Cámara de Diputados: 1840-1841 (Santiago, Imprenta Cervantes, 1903), XXVII.

-- Sesiones de los Cuerpos Lejislativos de la República de Chile (Santiago, Imprenta Cervantes, 1906), XXVIII.

-- Sesiones de los Cuerpos Legislativos de la República de Chile (Santiago, Imprenta Cervantes, 1906), XXIX.

-- Sesiones de los Cuerpos Legislativos de la República de Chile (Santiago, Imprenta Cervantes, 1905), XXX.

-- Sesiones de los Cuerpos Legislativos de la República de Chile (Santiago, Imprenta Cervantes, 1908), XXXI.

-- Sesiones de los Cuerpos Legislativos de la República de Chile (Santiago, Imprenta Cervantes, 1908), XXXVI.

-- Sesiones de los Cuerpos Legislativos de la República de Chile (Santiago, Imprenta Cervantes, 1908), XXXVII.

\section{Literatura}

Bravo Lira, Bernardino, Los comienzos de la codificación en Chile: la codificación procesal, en Revista Chilena de Historia del Derecho, 9 (Santiago, 1983), pp. 191- 210.

Bronfman, Alan, Documentos constitucionales de Chile 1811-1833, en Dippel, Horst (ed.), Constitutions of the World from the late 18th Century to the Middle of the 19th Century (München, K. G. Saur Verlag GmbH, 2006), II.

Carrasco Albano, Manuel, Comentarios sobre la Constitución Política de 1833 (Santiago, Imprenta de la Librería del Mercurio, 1874).

COLLIER, Simon, La construcción de una república. 1830-1865. Política e ideas (Santiago, Ediciones Universidad Católica de Chile, 2005).

Donoso, Ricardo, Las ideas politicas en Chile (3ra. Edición, Buenos Aires, Editorial Universitaria de Buenos Aires, 1975).

Encina, Francisco A., Historia de Chile (Santiago, Editorial Ercilla, 1984), XXII, XXV, XXIX.

Estévez Gazmuri, Carlos, Elementos de derecho constitucional chileno (Santiago, Editorial Jurídica de Chile, 1949). 
GuZmán Brito, Alejandro, Portales y el derecho (Santiago, Editorial Universitaria, 1988).

Heise González, Julio, Evolución histórica del pensamiento parlamentario en Chile (Santiago, Academia Chilena de Ciencias Sociales-Instituto de Chile, 1986).

Huneeus, Jorge, La Constitución ante el Congreso I, (2a edición, Santiago, Imprenta Cervantes, 1890).

-- La Constitución ante el Congreso II, (2a edición, Santiago, Imprenta Cervantes, 1891), tomo II.

Jara Cristi, Manuel, Derecho administrativo. Notas de clases y anexos legislativos (Santiago, s. e., 1936).

Lastarria, José Victorino, La Constitución Política de la República de Chile comentada (Valparaíso, Imprenta del Comercio, 1856).

Letelier, Valentín, La Gran Convención de 1831-1833 (Santiago de Chile, Imprenta Cervantes, 1901).

-- Génesis del Estado y de sus instituciones fundamentales. Introducción al estudio del derecho público (Buenos Aires, Cabaut y Cia. Editores, 1917).

RoldÁn, Alcibíades, Elementos de derecho constitucional de Chile (Santiago, Imprenta Barcelona, 1917).

Salazar, Gabriel, Construcción de Estado en Chile (1800-1837) (Santiago, Sudamericana, 2005).

Villalobos R., Sergio, Portales. Una falsificación histórica (4a edición, Santiago, Universitaria, 2005). 